\title{
A New Technique for Cytologic Examination of Hepatic Cells Obtained by Needle-Biopsy
}

\author{
By \\ Yuji Sato \\ From the Pediatric Clinic, National Hirosaki Hospital, Hirosaki; \\ and From the Department of Pediatrics, Faculty of Medicine, \\ Tohoku University, Sendai; Director: Prof. Ts. A r a k awa
}

(Received for publication, August 2, 1961)

It is usual that the biopsied specimens of the liver have been microscopically examined by such a traditional method as fixing, sectioning and staining, and it is also well experienced that details of cytologic changes of each of hepatic cells were unable to be observed by using ordinary histologic preparations, so it is desirable to be able to study the cellular morphology more precisely before going to the expense of using the electron microscope.

For cytologic examination of hepatic cells, Tischendorf ${ }^{1)}$ and Markof ${ }^{2)}$ devised a stamping-method, in which smears of hepatic cells were prepared by stamping directly a piece of the biopsied specimens of the liver upon a glass plate. But this Stamping-method was not satisfactory for precise observation of cytologic changes because of incompleteness of separation of hepatic cells from each other.

In the present paper I will report a new technique by which cytologic changes in each of hepatic cell obtained by needle biopsy can in many a case be observed even macroscopically.

\section{TECHNIQUE}

My Own Technique:- A piece of liver tissue, obtained by biopsy with Mitsuki's needle ${ }^{3 \prime}$ was put into a few cc of the serum of the very patient from whom the biopsied material was obtained, and "teased" gently with use of a pincette and needle so that part of hepatic cells fell off during the process and came to be free cells in the serum. Serum and all, then, was spread on a glass plate in the same way as in case of preparing blood smears. The smears thus obtained were air-dried, fixed with ethanol or other fixatives according to various staining methods. Sudan III, Best's carmine or the Giemsa stain were used.

佐 藤 雄 洽

This report was read at the First All-Asian Congress of Pediatrics, New Dehli, January, 1961. 
Figs. 1 and 2 showed how clearly demonstrated each of hepatic cells was. Both figures represented the materials obtained from children without hepatic disorder and stained by the Giemsa stain. Fig. 2 was the picture observed under low magnifying power; it would demonstrate successful separation of hepatic cells from each other. Fig. 1 showed a binucleated hepatic cell, in which uniform distribution of basophilic granules in cytoplasm was clearly seen under high magnifying power.

Cytologic changes of hepatic cells in the cases with various diseases will be reported in the near future.

\section{SUMMARY}

A new technique for cytologic examination of hepatic cells obtained by needle biopsy was described. In this method cells were so well separated from each other and so clearly seen, that coarse changes might be observed even macroscopically.

I wish to thank Prof. K. C. Chaudhuri, President of the First All-Asian Congress of Pediatrics, New Dehli, 1961, who gave Dr. Y. Sato an oppotunity to read this report and who showed so great an interest in this investigation of Dr. Sato's as is shown in the president's description-"This method obviously has great potentialities and may elucidate cytological changes in diseased organs which have so far eluded observation. It should not be too long before Sato's method becomes universally recognized" (Indian J. Pediatr., 1961, 28, 156).

Prof. Ts. Arakawa

\section{References}

1) Tischendorf, W., Dtsch. med. Wschr., 1951, 76, 300.

2) Markof, N., Schweiz. med. Wschr., 1950, 80, 93.

3) Mitsuki, K., Diagnostic Method By Organ Puncture (Jap.), lst ed., Kanehara, Osaka, Japan, 1953. 


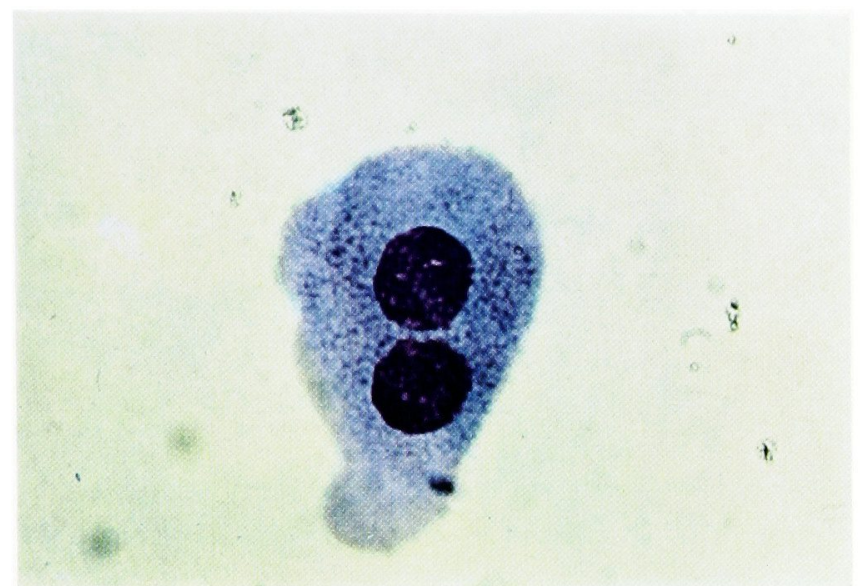

Fig. 1. A binucleated hepatic cells under high magnifying power.



Fig. 2. Hepatic cells, clearly separated from each other, were demonstrated under low magnifying power. 